\title{
Early diagnosis and secondary prevention of Duchenne muscular dystrophy
}

\author{
R A SMITH, ${ }^{*} \mathrm{~J}$ R SIBERT, $\dagger \mathrm{S} \mathrm{J}$ WALLACE, $\uparrow$ AND P S HARPER* \\ Institute of *Medical Genetics and †Department of Child Health, University of Wales College of Medicine, \\ Cardiff
}

SUMMARY A total of 33 young boys (mean age 3.4 years) with Duchenne muscular dystrophy and 21 normal controls (mean age 3.5 years) were assessed using the Griffiths's mental development scales and the Reynell language scales. The boys with Duchenne muscular dystrophy were significantly developmentally delayed when compared with the control group. The developmental delay was most pronounced in locomotor function and language. There was no significant difference in social class distribution. Early diagnosis of Duchenne muscular dystrophy is of vital importance if secondary cases within families are to be prevented. While diagnosis is still unacceptably late in most cases, it can be improved if all boys with this pattern of developmental delay are screened for Duchenne muscular dystrophy by measurement of creatine kinase activity.

Recent advances in the understanding of the molecular genetics of Duchenne muscular dystrophy have led to improvements in the determination of female carrier status and to the provision of reliable antenatal diagnosis for most pregnancies at high risk. ${ }^{1}$ These advances highlight the importance of early diagnosis of Duchenne muscular dystrophy. Prevention of secondary cases within a kindred could now be achieved if early diagnosis was improved and genetic counselling offered. Early diagnosis is important for other reasons: it avoids the frustration for the parents of late diagnosis when symptoms have been ignored or misinterpreted, it allows for early comprehensive assessment and management, and has been shown to be wanted by parents. $^{2}$

There are no obvious clinical signs of Duchenne muscular dystrophy in affected young boys. There are, also, no studies of large samples of young boys with Duchenne muscular dystrophy. We aim to show that by studying the early development of young boys with Duchenne muscular dystrophy a pattern of aberrant development can be demonstrated, which is helpful in directing attention to the possibility of this disease.

\section{Subjects and methods}

We studied 33 young boys with Duchenne muscular dystrophy from 31 families. The average age on entry to the study was 3.4 years (range 0.8 to 6.4 ). Nineteen were from Wales and 14 were ascertained from various centres in England through paediatric and medical genetic units. They formed a heterogeneous group. Twelve were diagnosed in the asymptomatic phase because of a family history, 12 presented with developmental delay, and nine presented with locomotor problems. All had very high creatine kinase activities. Twenty four had the diagnosis confirmed by a muscle biopsy specimen and the remaining nine had a positive family history with an affected relative who had had a confirmatory muscle biopsy. In none of the families was the pattern of disease suggestive of Becker muscular dystrophy. A control group of 21 normal boys, matched for age, were recruited from the Cardiff birth register.

Formal developmental assessments were carried out on both groups of boys using the Griffiths's mental development scales ${ }^{3}$ and the Reynell language scales. ${ }^{4}$ All assessments were carried out by one observer (RAS) in the subject's home; this was deemed to be the best environment to obtain maximum cooperation.

The Griffiths's mental development scales are a widely used set of scales standardised on normal British children. They assess six main areas of development: locomotor, personal-social, hearingspeech, eye-hand coordination, performance, and practical reasoning. The practical reasoning scale 
starts at the third year. Scores are given as a mental age in months, based on items scored, which when divided by the actual age gives a quotient for each subscale. The overall general quotient is the mean of the subquotients. The current mean quotients on the Griffiths's scales for normal children are 110; this reflects the out of date standardisation of the Griffiths's scales.

The Reynell language scales are standardised on normal British children and assess verbal comprehension and expressive language. The scores are given in terms of equivalent age levels and standard scores. This scale has been recently restandardised.

Statistical analysis was performed using the Student's $t$ test and $\chi^{2}$ test.

\section{Results}

The overall mean developmental quotients and mean subscale quotients achieved by both groups of boys on the Griffiths's scales are presented in table 1 . The scores achieved by the boys with Duchenne muscular dystrophy were significantly lower than the control group on all subscales with a more noticeable discrepancy on the locomotor and hearing-speech subscales. Seventeen $(52 \%)$ boys with Duchenne muscular dystrophy scored below 80 on overall Griffiths's quotient, $28(85 \%)$ scored below 80 on the locomotor subscale, and $20(61 \%)$ scored below 80 on the hearing-speech subscale. Only 18 boys with Duchenne muscular dystrophy scored items on the practical reasoning scale, which explains the larger standard deviation.

The mean scores of the subgroups of the group with Duchenne muscular dystrophy, based on mode of presentation, are presented in table 2. The pattern of subscale scores was similar for all three groups. The group diagnosed in the asymptomatic phase, because of a positive family history, had the

Table 1 Griffiths's subscales mean (SD) quotients

\begin{tabular}{lllr}
\hline Subscale & $\begin{array}{l}\text { Boys with } \\
\text { Duchenne } \\
\text { muscular } \\
\text { dystrophy } \\
(n=33)\end{array}$ & $\begin{array}{l}\text { Controls } \\
(n=21)\end{array}$ & $t$ \\
& & & \\
\hline Locomotor & $65(13)$ & $112(9)$ & $15 \cdot 5^{*}$ \\
Personal-social & $81(17)$ & $110(16)$ & $6 \cdot 4^{*}$ \\
Hearing-speech & $77(19)$ & $110(16)$ & $6 \cdot 9^{*}$ \\
Eye-hand coordination & $82(16)$ & $108(12)$ & $6 \cdot 9^{*}$ \\
Performance & $88(15)$ & $116(18)$ & $5 \cdot 9^{*}$ \\
Practical reasoning & $86(21) \dagger$ & $112(17)$ & $4 \cdot 9^{*}$ \\
General quotient & $79(14)$ & $111(12)$ & $8 \cdot 6^{*}$ \\
Age (years) & $3.4(1 \cdot 6)$ & $3 \cdot 5(1 \cdot 5)$ & \\
\hline
\end{tabular}

${ }^{*} \mathrm{p}<0.001 ; \mathrm{tn}=18$.
Table 2 Griffiths's subscales mean (SD) quotients for boys with Duchenne muscular dystrophy

\begin{tabular}{llll}
\hline Subscale & $\begin{array}{l}\text { Developmental } \\
\text { delay } \\
(n=12)\end{array}$ & $\begin{array}{l}\text { Locomotor } \\
\text { delay } \\
(n=9)\end{array}$ & $\begin{array}{l}\text { Positive } \\
\text { family } \\
\text { history } \\
(n=12)\end{array}$ \\
\hline Locomotor & 62 & 58 & 77 \\
Personal-social & 75 & 82 & 85 \\
Hearing-speech & 70 & 82 & 81 \\
Eye-hand coordination & 78 & 84 & 87 \\
Performance & 83 & 90 & 92 \\
Practical reasoning & $85(\mathrm{n}=6)$ & $84(\mathrm{n}=5)$ & 92 \\
General quotient & 74 & 80 & 85 \\
Age (years) & $2 \cdot 8$ & $5 \cdot 2$ & $2 \cdot 6$ \\
\hline
\end{tabular}

lowest mean age and still show developmental delay. The group presenting later, with locomotor problems, had a higher mean age and the lowest locomotor score. The group presenting with developmental delay had the lowest mean language score.

The mean equivalent age and mean standard scores for the Reynell language scales are given in table 3 . The two youngest boys age 10 months and 1 year 2 months were unable to perform any tasks on the Reynell scales. There is a highly significant difference between the standardised scores of the Duchenne muscular dystrophy group and the control group for both the verbal comprehension scale $A$ and the expressive language scale. The control group had mean standard scores close to zero reflecting the more up to date standardisation of this scale.

Table 4 shows that there was no significant difference in social class distribution between the subgroups of boys with Duchenne muscular dystrophy or between the group with Duchenne muscular dystrophy as a whole and the control group.

Table 3 Reynell language scales mean scores. The standard scores are given as $S D$

\begin{tabular}{llll}
\hline Scale & $\begin{array}{l}\text { Boys with } \\
\text { Duchenne } \\
\text { muscular } \\
\text { dystrophy } \\
(n=31)\end{array}$ & $\begin{array}{l}\text { Controls } \\
(n=21)\end{array}$ & $t$ \\
\hline $\begin{array}{l}\text { Verbal } \\
\text { comprehension A } \\
\text { equivalent age (years) }\end{array}$ & 2.6 & 3.7 & \\
$\begin{array}{l}\text { Verbal } \\
\text { comprehension A } \\
\text { standard score }\end{array}$ & -1.53 & 0.16 & $6.5^{*}$ \\
$\begin{array}{l}\text { Expressive language } \\
\text { equivalent age (years) }\end{array}$ & 2.45 & 3.3 & \\
$\begin{array}{l}\text { Expressive language } \\
\text { standard score }\end{array}$ & -1.74 & -0.38 & $5.5^{*}$ \\
$\begin{array}{l}\text { Age (years) } \\
\text { (y) }\end{array}$ & 3.6 & 3.5 & \\
\hline
\end{tabular}

${ }^{*} \mathrm{p}<0.001$. 
Table 4 Social class distribution

\begin{tabular}{|c|c|c|c|c|c|}
\hline \multirow[t]{2}{*}{ Social class } & \multicolumn{3}{|c|}{$\begin{array}{l}\text { Subgroups for Duchenne muscular } \\
\text { dystrophy (presentation) }\end{array}$} & \multirow{2}{*}{$\begin{array}{l}\text { Total boys } \\
\text { with Duchenne } \\
\text { muscular dystrophy }\end{array}$} & \multirow[t]{2}{*}{ Controls } \\
\hline & $\begin{array}{l}\text { Developmental } \\
\text { delay }\end{array}$ & $\begin{array}{l}\text { Locomotor } \\
\text { delay }\end{array}$ & $\begin{array}{l}\text { Positive } \\
\text { family history }\end{array}$ & & \\
\hline 1 & 2. & 0 & 0 & 2 & 2 \\
\hline 2 & 3 & 2 & 0 & 5 & 7 \\
\hline 3 manual & 4 & 2 & 4 & 10 & 6 \\
\hline 3 non-manual & & & 1 & 1 & 0 \\
\hline 4 & 1 & 1 & 2 & 4 & 1 \\
\hline 5 & 1 & 0 & 1 & 2 & 0 \\
\hline Unemployed & 1 & 4 & 4 & 9 & 5 \\
\hline Total & 12 & 9 & 12 & 33 & 21 \\
\hline
\end{tabular}

For difference between Duchenne muscular dystrophy and controls $0 \cdot 5>p>0 \cdot 10$.

\section{Discussion}

Locomotor delay and delay in language development have previously been reported. ${ }^{56}$ Most information on early development in Duchenne muscular dystrophy, however, has been obtained retrospectively. The existence of early global developmental delay and the extent of delay in language development has not previously been reported. The Griffiths's and Reynell scales are often used by paediatricians in their initial assessment of children with developmental delay. Recognition of the pattern of developmental delay, which is shown in the present study, even in the youngest boys could lead to earlier diagnosis and improve secondary prevention rates.

The differences between the two groups of boys is too great to be explained by differences in social class or child rearing practices. Only one boy in the group with Duchenne muscular dystrophy and none in the control group had failed the routine hearing tests.

Despite efforts to encourage early diagnosis, ${ }^{7-10}$ the detection of new cases of Duchenne muscular dystrophy remains unsatisfactorily late in most cases. Between 1970 and 1979, 43 boys were born in Wales who were later found to have Duchenne muscular dystrophy. During this period near complete ascertainment has been achieved. A population incidence for this period has been calculated to be $1 / 4400$ based on estimated figures for boys born during this period and living to the age of 5 years. This figure is similar to other calculated population incidences. ${ }^{11}$

Accurate ages of diagnosis have been obtained from the clinical notes for $36(84 \%)$ of these 43 cases. The mean age at diagnosis for these 36 boys is 4.9 years. This group can be subdivided into 25 first cases and 11 familial cases. The mean ages at diagnosis for these two groups is $5 \cdot 2$ years and 4.3 years respectively, suggesting that even a positive family history does not necessarily decrease age at diagnosis. Ages at diagnosis of various cohorts of boys with Duchenne muscular dystrophy have been determined to be 5.8 years, ${ }^{8} 5.7$ years, ${ }^{8}$ and 4.7 years. ${ }^{9}$ Thus late diagnosis remains a problem in Duchenne muscular dystrophy.

Secondary prevention is the main advantage of early diagnosis. Estimates for the number of theoretically preventable cases by neonatal screening vary. Thirteen per cent of 122 cases ascertained in the north east of England, ${ }^{8} 10-12 \%$ in a cohort of patients in the Midlands, ${ }^{8}$ and $8 \cdot 3 \%$ of secondary cases could be prevented by neonatal screening for affected boys purely on theoretical grounds. ${ }^{12}$ In the series of 43 patients born between 1970 and 1979 in Wales there were $28(65 \%)$ isolated cases and 15 $(35 \%)$ had more than one case per family. Five of the 43 cases $(12 \%)$ could have been prevented by the earlier diagnosis of an affected sibling or cousin.

There are three main strategies available to improve early diagnosis: neonatal screening of all male births; screening of selected infant populations, and reliance on clinical diagnosis. Although newborn screening is certainly feasible, ${ }^{13-15}$ in the absence of effective treatment for Duchenne muscular dystrophy it has not found favour in Britain. A screening programme involving testing boys for creatine kinase activity at the routine 6 week infant check up exists in West Germany. ${ }^{16}$ The programme is voluntary, however, and the uptake has been low (14\%). Based on retrospective data that showed that $50 \%$ of boys with Duchenne muscular dystrophy are not walking at 18 months, Gardner-Medwin proposed that those boys not walking at this age be tested for creatine kinase activity and this could be used as the basis for a screening programme. ${ }^{8}$ 
At present a population screening programme based on testing boys for creatine kinase activity who are unable to walk four independent steps at 18 months (when they have their routine developmental assessment by a health visitor) is being conducted in Wales, but it is too early to draw conclusions on its effectiveness.

We conclude that early diagnosis could be improved, even without population screening, if all boys with unexplained overall developmental delay, but with more noticeable delay in locomotor and language abilities, are systematically tested for Duchenne muscular dystrophy by measuring their serum creatine kinase activity.

We would like to thank the Muscular Dystrophy Group of Great Britain and Northern Ireland and all the consultants who provided patients for the study.

\section{References}

' Forrest SM, Cross GS, Thomas NST, et al. Effective strategy for prenatal prediction of Duchenne and Becker muscular dystrophy. Lancet 1987;ii: 1294-6.

2 Firth MA, Wilkinson J. Screening for Duchenne muscular dystrophy: parents views. Br Med J 1983;286:1933-4.

${ }^{3}$ Griffiths RG. The abilities of young children. A comprehensive system of study for the first eight years of life. High Wycombe: The Test Agency, 1970.

${ }^{4}$ Reynell J. Manual for the Reynell development language scales. 2nd revision by $M$ Huntley. Windsor: National Foundation of Education Research, 1985.
${ }^{5}$ Kaplan LC, Osborne P, Elias E. The diagnosis of muscular dystrophy in patients referred for language delay. J Child Psychol Psychiatry 1986;27:545-9.

6 Marsh GM, Munsat LM. Evidence for early impairment of verbal intelligence in Duchenne muscular dystrophy. Arch Dis Child 1974;49:118-22.

7 Gardner-Medwin D. Recognising and preventing Duchenne muscular dystrophy. Br Med J 1983;287:1083-4.

8 Gardner-Medwin D, Bundey S, Green S. Early diagnosis of Duchenne muscular dystrophy. Lancet 1978;i:1102.

${ }^{9}$ Crisp DE, Ziter FA, Bray PF. Diagnostic delay in Duchenne muscular dystrophy. JAMA 1982;247:478-90.

10 O'Brien T, Sibert JR, Harper PS. Implications of diagnostic delay in Duchenne muscular dystrophy. $\mathrm{Br}$ Med $J$ 1983;287: 1106.

"Moser H. Duchenne muscular dystrophy: pathogenesis and genetic prevention. Hum Genet 1984;66:17-40.

12 Grimm T. Neugeborenen-screening nach Duchennscher muskeldystrophie. Monatsschr Kinderheilkd 1981;129:414-7.

13 Drummond LM. Creatine phosphokinase levels in the newborn and their use in screening for Duchenne muscular dystrophy. Arch Dis Child 1979;54:362-6.

14 Dellamonica C, Robert JM, Cottee J, Collanbell C, Dorche C. Systematic screening for Duchenne muscular dystrophy. Lancet 1978;ii: 1100 .

15 Skinner R, Emery AEH, Scheuerbrandt G, Syme J. Feasibility of newborn screening for Duchenne muscular dystrophy. J Med Genet 1982;19:1-3.

${ }^{16}$ Scheuerbrandt G, Lundin A, Lovgren T, Mortier W. Screening for Duchenne muscular dystrophy: an improved screening test for creatine kinase and it's application in an infant screening programme. Muscle Nerve 1986;9:11-23.

Correspondence to Dr RA Smith, Institute of Medical Genetics, Heath Park, Cardiff CF4 4XN.

Accepted 13 January 1989 